\title{
Study on Concrete Activation Reduction in a PET Cyclotron Vault
}

\author{
Mahdi Bakhtiari' ${ }^{1}$, Leila Mokhtari Oranj' ${ }^{2}$ Nam-Suk Jung ${ }^{2}$, Arim Lee², Hee-Seock Lee ${ }^{1,2}$ \\ ${ }^{1}$ Division of Advanced Nuclear Engineering, Pohang University of Science and Technology (POSTECH), Pohang, Korea; ${ }^{2}$ Pohang Accelerator Laboratory, \\ Pohang University of Science and Technology (POSTECH), Pohang, Korea
}

\section{Original Research}

Received June 7, 2020

Revision August 7, 2020

Accepted September 5, 2020

Corresponding author: Hee-Seock Lee

Department of Radiation Protection, Pohang Accelerator Laboratory, Pohang University of Science and Technology, 80 Jigok-ro 127beon-gil, Nam-gu, Pohang 37673, Korea

E-mail: lee@postech.ac.kr

(iD https://orcid.org/0000-0002-7285-481X

This is an open-access article distributed under the terms of the Creative Commons Attribution License (http://creativecommons.org/licenses/by-nc/4.0), which permits unrestricted use, distribution, and reproduction in any medium, provided the original work is properly cited.

\section{Copyright $\odot 2020$ The Korean Association for} Radiation Protection

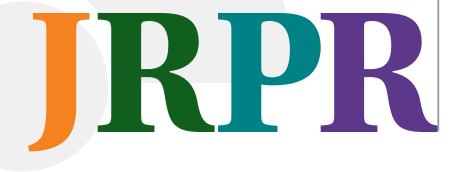

\section{Introduction}

Medical proton cyclotrons operating below $20 \mathrm{MeV}$ are used to produce radioiso-

topes for medical diagnostic imaging. Typical short-lived radioisotopes used in posithe thermal neutron flux at certain depths inside the concrete was calculated for each condition. Subsequently, the optimum combination was determined with respect to radioactive waste reduction, price, and availability, and the total reduced radioactive concrete waste was estimated.

Results and Discussion: In the specific conditions considered in this study, the front wall with respect to the proton beam contained radioactive waste with a depth of up to $64 \mathrm{~cm}$ without any additional shield. A single layer of additional shield was inefficient because a thick shield was required. Two-layer combinations comprising 0.1- or 0.4-cm-thick $\mathrm{B}_{4} \mathrm{C}$ or $\mathrm{Gd}_{2} \mathrm{O}_{3}$ behind $10 \mathrm{~cm}$ thick PE were studied to verify whether the appropriate thickness of the additional shield could be maintained. The number of transmitted thermal neutrons reduced to $30 \%$ in case of $0.1 \mathrm{~cm}$ thick $\mathrm{Gd}_{2} \mathrm{O}_{3}+10 \mathrm{~cm}$-thick PE or $0.1 \mathrm{~cm}$-thick $\mathrm{B}_{4} \mathrm{C}+10 \mathrm{~cm}$-thick PE. Thus, the thickness of the radioactive waste in the front wall was reduced from 64 to $48 \mathrm{~cm}$.

Conclusion: Based on price and availability, the combination of the $10 \mathrm{~cm}$-thick $\mathrm{PE}+0.1 \mathrm{~cm}$ thick $\mathrm{B}_{4} \mathrm{C}$ was reasonable and could effectively reduce the number of thermal neutrons. The amount of radioactive concrete waste was reduced by factor of two when considering whole concrete walls of the PET cyclotron vault.

Keywords: Concrete Activation Reduction, PHITS Code, PE, $\mathrm{B}_{4} \mathrm{C}, \mathrm{Gd}_{2} \mathrm{O}_{3}$, PETtrace Cyclotron
Background: Concrete activation in cyclotron vaults is a major concern associated with their decommissioning because a considerable amount of activated concrete is generated by secondary neutrons during the operation of cyclotrons. Reducing the amount of activated concrete is important because of the high cost associated with radioactive waste management. This study aims to investigate the capability of the neutron absorbing materials to reduce concrete activation.

Materials and Methods: The Particle and Heavy Ion Transport code System (PHITS) code was used to simulate a cyclotron target and room. The dimensions of the room were $457 \mathrm{~cm}$ (length), $470 \mathrm{~cm}$ (width), and $320 \mathrm{~cm}$ (height). $\mathrm{Gd}_{2} \mathrm{O}_{3}, \mathrm{~B}_{4} \mathrm{C}$, polyethylene (PE), and borated (5 $\left.{ }_{w t} \%{ }^{\text {nat }} \mathrm{B}\right) \mathrm{PE}$ with thicknesses of 5,10 , and $15 \mathrm{~cm}$ and their different combinations were selected as neutron absorbing materials. They were placed on the concrete walls to determine their effects on thermal neutrons. Thin $\mathrm{B}_{4} \mathrm{C}$ and $\mathrm{Gd}_{2} \mathrm{O}_{3}$ were placed between the concrete wall and additional PE shield separately to decrease the required thickness of the additional shield, and 
tron emission tomography (PET) are ${ }^{11} \mathrm{C},{ }^{13} \mathrm{~N},{ }^{15} \mathrm{O}$, and ${ }^{18} \mathrm{~F}$ among which ${ }^{18} \mathrm{~F}$ is in particular interest. More than 40 cyclotrons are installed in Korea including 20 non-self-shielded cyclotrons. These cyclotron facilities are expected to be dismantled before the designed lifespan due to upgrade, changes of purpose and place of use, etc. Activated materials inside the cyclotron vault and in concrete walls result in radiological hazards during the maintenance and decommissioning stage, respectively. Additionally, a huge amount of radioactive waste will be generated, after a long period of cyclotron operation, which is one of the main issues during the decommissioning stage because of the high cost of radioactive waste management. The primary radionuclides that cause the concrete activation are ${ }^{152} \mathrm{Eu}\left(\mathrm{T}_{1 / 2}=13.52 \mathrm{y}\right)$ and ${ }^{60} \mathrm{Co}$ $\left(\mathrm{T}_{1 / 2}=5.27 \mathrm{y}\right)$. Although ${ }^{151} \mathrm{Eu}$ and ${ }^{59} \mathrm{Co}$ are trace element in the concrete constitutes, they have significant thermal neutron absorption cross sections (Table 1). After a long operation, the specific activities will exceed the order of clearance level [1-3]. The clearance level of the radionuclide in this work is based on the international standards [4]. A material is disregarded as the radioactive waste based on the following clearance criterion:

$$
\sum_{i} \frac{C_{i}}{C_{L_{i}}} \leq 1
$$

where $C_{i}$ is the specific activity of the isotope $i\left(\mathrm{~Bq} \cdot \mathrm{g}^{-1}\right)$ and $C_{L_{i}}$ is the clearance level for the isotope $i\left(\mathrm{~Bq} \cdot \mathrm{g}^{-1}\right)$.

The goal of this work is to reduce the total volume of radioactive concrete waste by a factor of two by considering the capability, availability, and the cost of the shielding materials. To achieve this goal, the thermal neutrons, which are responsible for the induced radioactivity in the concrete, were reduced by using the absorbing materials and the reduced amount of activated concrete was estimated. Activation reduction methods are important to decrease the activation level of the concrete in the depth for non-self-shielded cyclotrons that are already installed and are in operation.

Table 1. Major Radionuclides in Concrete and Corresponding Characteristics

\begin{tabular}{lcccc}
\hline $\begin{array}{l}\text { Radionu- } \\
\text { clide }\end{array}$ & Reaction & Half-life & $\begin{array}{c}\text { Thermal neutron } \\
\text { absorption cross } \\
\text { section }(\text { barn })[17,23]\end{array}$ & $\begin{array}{c}\text { Clearance } \\
\text { level } \\
\left(\mathrm{Bq} \cdot \mathrm{g}^{-1}\right)\end{array}$ \\
\hline${ }^{152} \mathrm{Eu}$ & $\left.{ }^{151} \mathrm{Eu}(\mathrm{n}, \gamma)\right)^{152} \mathrm{Eu}$ & $13.52 \mathrm{yr}$ & 5,900 & 0.1 \\
${ }^{134} \mathrm{Cs}$ & $\left.{ }^{133} \mathrm{Cs}(\mathrm{n}, \gamma)\right)^{134} \mathrm{Cs}$ & $2.06 \mathrm{yr}$ & 29 & 0.1 \\
${ }^{60} \mathrm{Co}$ & ${ }^{59} \mathrm{Co}(\mathrm{n}, \gamma){ }^{60} \mathrm{Co}$ & $5.27 \mathrm{yr}$ & 37 & 0.1 \\
${ }^{46} \mathrm{Sc}$ & ${ }^{45} \mathrm{Sc}(\mathrm{n}, \gamma)^{46} \mathrm{Sc}$ & 83.79 day & 26.5 & 0.1 \\
\hline
\end{tabular}

Several researchers have proposed different ways to reduce the amount of radioactive waste such as using low activation concrete $[5,6]$, or reusing the low activated materials [7]. One effective method is to use neutron absorbing materials with high neutron capture cross sections. In addition to the conventional shielding materials as polyethylene (PE) and borated polyethylene (BPE), other novel materials such as boron carbide, and gadolinium are gaining interest $[1,8]$. In this work, the effects of conventional and novel materials are considered and discussed. These materials can be used around the target or on the walls [9] in order to absorb thermal neutrons and consequently to reduce the activated concrete. A non-self-shielded PETtrace cyclotron (GE Healthcare, Chicago, IL, USA) has been selected to investigate the neutron reduction method by Monte Carlo code, Particle and Heavy Ion Transport code System (PHITS) version 3.02 [10]. The PETtrace is one of the popular medical cyclotrons which are used to generate ${ }^{18} \mathrm{~F}$ by impinging $16.5-\mathrm{MeV}$ protons on a water target with enriched ${ }^{18} \mathrm{O}$ via ${ }^{18} \mathrm{O}(\mathrm{p}, \mathrm{n}){ }^{18} \mathrm{~F}$ reaction. In our previous work, the neutron production yields from the $\mathrm{H}_{2}{ }^{18} \mathrm{O}$ target have been investigated [11]. The secondary neutrons that are produced along with ${ }^{18} \mathrm{~F}$ activate the surrounding materials and the bulk concrete, especially, in case of non-self-shielded PET cyclotrons [2, 12-14].

\section{Materials and Methods}

In order to consider the activity reduction in the concrete, a geometry of an $\mathrm{H}_{2}{ }^{18} \mathrm{O}$ target and a cyclotron vault was simulated in PHITS-3.02 code [10] as shown in Fig. 1. In the PHITS code, by default, proton-induced reactions at energies up to $3 \mathrm{GeV}$ are simulated by the intra-nuclear cascade of Liège model version 4.6 (INCL-4.6) [15]. The INCL-4.6 model is followed by the generalized evaporation model (GEM) [16]. In this simulation, JENDL-4.0 [17] cross sections library was applied for neutron interactions. INCL-4.6 was used for proton-induced reactions on ${ }^{18} \mathrm{O}$.

The dimension of the cyclotron vault was $457 \mathrm{~cm}$ in length, $470 \mathrm{~cm}$ in width and $320 \mathrm{~cm}$ in height. The neutron spectrum in the forward direction was scored before reaching the concrete (position 1 in Fig. 1). Position 1 was selected in this study as it is in the forward direction with respect to the proton beam and the maximum neutron flux is expected. The spherical detector radius is $10 \mathrm{~cm}$ and distance to the concrete wall is $40 \mathrm{~cm}$. Thermal neutrons in the concrete at different depths were scored as well (positions 2, 3, and 4 in Fig. 1). Other tal- 

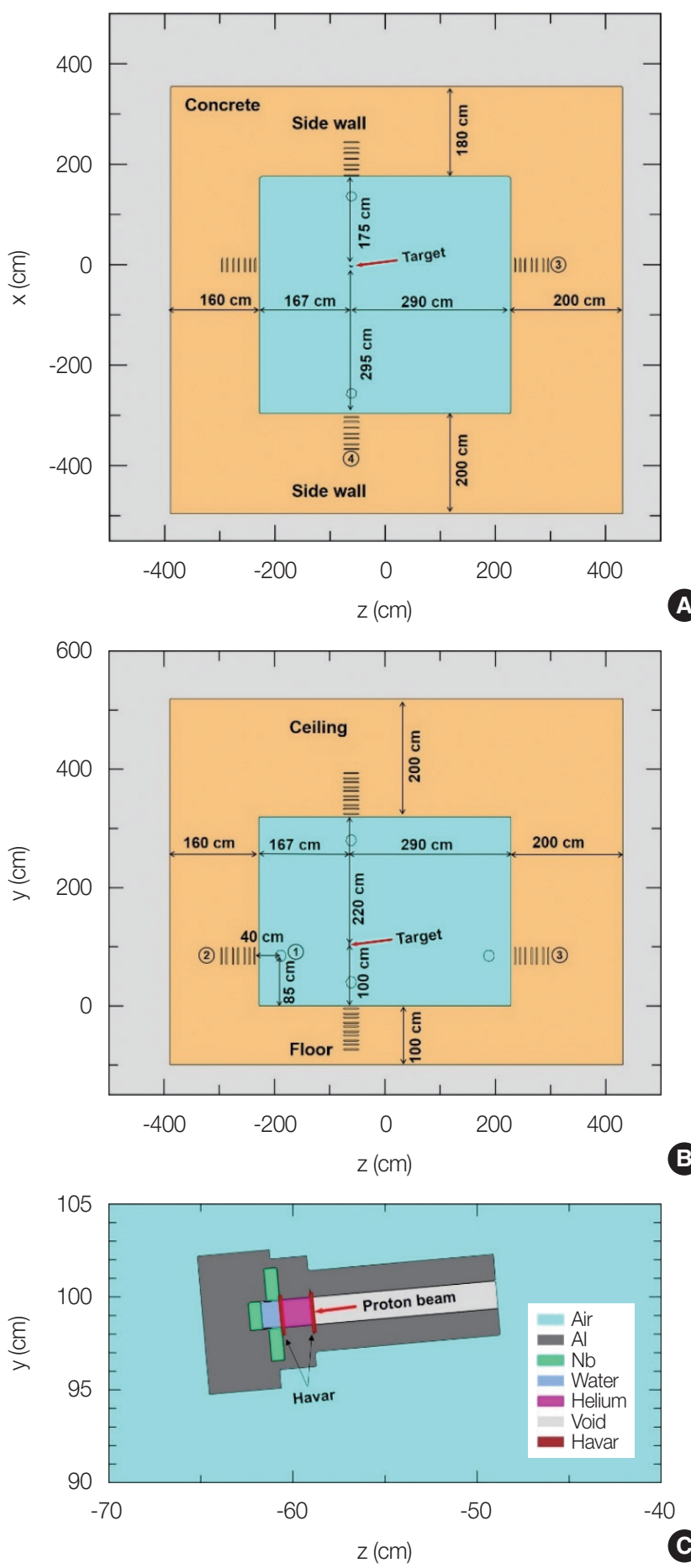

Fig. 1. PETtrace room geometry simulated using the PHITS code (A) top view, (B) vertical view, (C) 16.5-MeV proton beam striking the $\mathrm{H}_{2}{ }^{18} \mathrm{O}$ target. Neutron spectra were scored inside the room and in the concrete at positions 1, 2, 3, and 4, respectively. The size of the room is $457 \mathrm{~cm}$ in length, $470 \mathrm{~cm}$ in width and $320 \mathrm{~cm}$ in height. PHITS, Particle and Heavy lon Transport code System.

lies were also used to score the neutrons at different directions as shown in Fig. 1. However, the results from positions

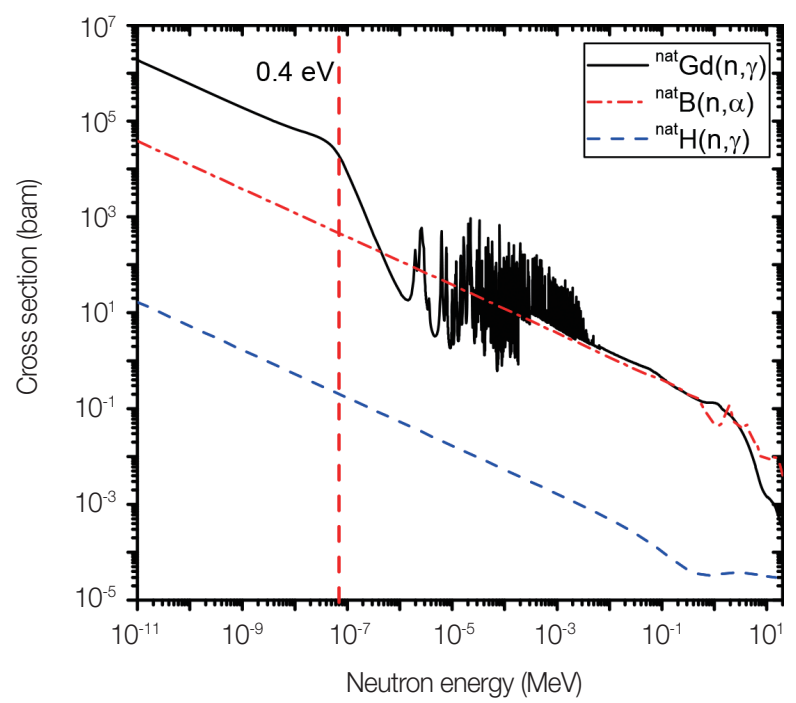

Fig. 2. Neutron absorption cross sections for nat $G d$, nat $B$, and nat $H$ taken from JENDL-4.0 [17]. The vertical dashed line indicates the thermal neutron energy of $0.4 \mathrm{eV}$.

$1,2,3$, and 4 are shown in this work. In this simulation, the concrete wall was divided into layers with the dimensions of $30 \times 30 \mathrm{~cm}^{2}$ and the thickness of $3 \mathrm{~cm}$. Neutrons were scored at each layer using the [T-Track] tally in the PHITS code. The scored neutron fluence was folded with the cross sections taken from JENDL-4.0 to consider the impact of the thermal, epithermal and fast neutrons on the radionuclides production. The thickness of the $\mathrm{H}_{2}{ }^{18} \mathrm{O}$ target was $1.04 \mathrm{~cm}$ with a diameter of $1.4 \mathrm{~cm}$. The target is bombarded with $16.5-\mathrm{MeV}$ protons. The radioactivity is due to trace element in the concrete such as Eu and Co. The magnitude of activation will highly depend on the concrete composition. In this calculations, concrete compositions are taken from PAL-XFEL-2017 (Pohang Accelerator Laboratory X-ray Free Electron Laser) [18] with the density of $2.337 \mathrm{~g} \cdot \mathrm{cm}^{-3}$.

The operation scheme was selected based on the survey that was conducted about the cyclotrons in Korea [19] so that the maximum operation frequency and daily operation was selected to be 5 days per week and 4 hours a day. Additionally, it is expected that many of the cyclotrons would stop the operation before 10 years because of upgrade, changes of purpose, and place of use [20]. Therefore, the operation scheme in this work is quite conservative.

Boron, gadolinium, and hydrogen have high neutron absorption cross sections (Fig. 2) so that they can reduce thermal neutrons significantly and in case of hydrogen, it is relatively an effective neutron moderator. The whole walls of the cyclotron vault were then covered by neutron absorbing ma- 
terials so as the effects of each material could be investigated separately. In the calculations, $\mathrm{Gd}_{2} \mathrm{O}_{3}\left(7.407 \mathrm{~g} \cdot \mathrm{cm}^{-3}\right), \mathrm{B}_{4} \mathrm{C}$ $\left(2.52 \mathrm{~g} \cdot \mathrm{cm}^{-3}\right)$, BPE $\left(1.01 \mathrm{~g} \cdot \mathrm{cm}^{-3}\right)$, and PE $\left(0.94 \mathrm{~g} \cdot \mathrm{cm}^{-3}\right)$, with thicknesses of 5,10 , and $15 \mathrm{~cm}$ were considered for each material. In addition, a combination of $\mathrm{PE}+\mathrm{Gd}_{2} \mathrm{O}_{3}$, and $\mathrm{PE}+\mathrm{B}_{4} \mathrm{C}$ were studied as well. Optimum material was determined by considering the thermal neutron absorption capability, the material cost and availability. Finally, the concrete thickness to be the radioactive waste were determined.

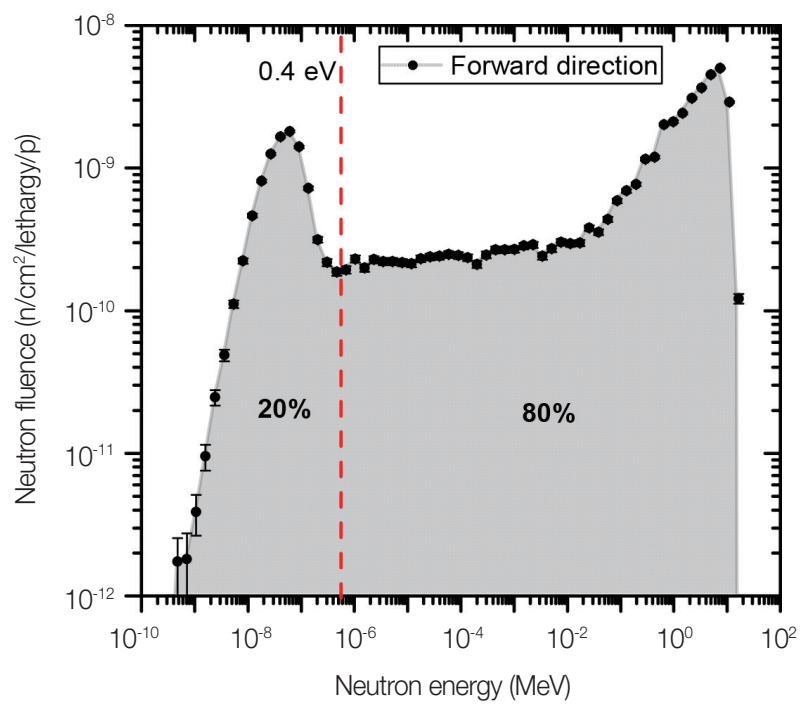

Fig. 3. Neutron spectrum in the forward direction respect to the proton beam indicated as position 1 in Fig. 1 at $40 \mathrm{~cm}$ before the concrete. The spectrum contains 20\% thermal neutrons and $80 \%$ epithermal and fast neutrons. The vertical dashed line indicates the thermal neutron energy of $0.4 \mathrm{eV}$.

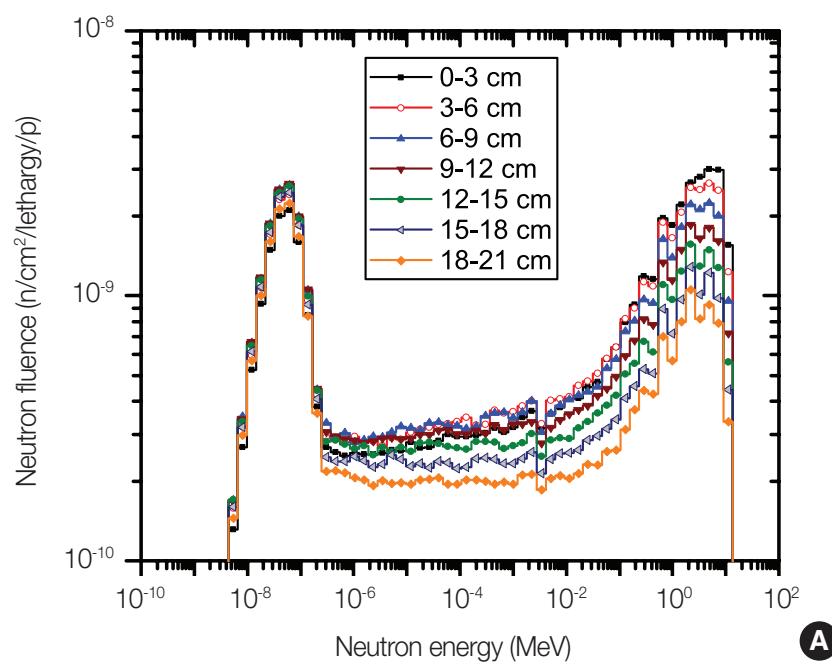

\section{Results and Discussion}

\section{Thermal Neutron Depth Profile}

The neutron spectrum in the forward direction was scored before reaching the concrete (position 1 in Fig. 1) and is shown in Fig. 3. The spectrum contains $20 \%$ thermal neutrons and $80 \%$ epithermal and fast neutrons that can be down-scattered to thermal neutrons. The neutron spectra without any absorbing material are shown in Fig. 4A at several concrete depths. It is seen that fast neutrons are higher at the very beginning of the concrete depth and decrease as the concrete thickness increases. On the other hand, the number of thermal neutrons increases in the higher depths of concrete. Suppressing these thermal neutrons is extremely important to reduce the radioactivity in the concrete. The impact of the epithermal and fast neutrons on the ${ }^{152} \mathrm{Eu}$ and ${ }^{60} \mathrm{Co}$ production were also considered. Even though considering the wall position where those flux are maximum, the contribution of the epithermal and fast neutrons to the production of ${ }^{152} \mathrm{Eu}$ was less than $10 \%$, while they contribute to the ${ }^{60} \mathrm{Co}$ production by $15 \%$ at the concrete surface and in the deeper positions it was less than $10 \%$. Therefore, the thermal neutrons were the major concern in the ${ }^{152} \mathrm{Eu}$ and ${ }^{60}$ Co production.

Fig. 4B shows the integrated thermal neutron fluence for energies less than $0.4 \mathrm{eV}$ as a function of concrete depth, and illustrates that thermal neutron fluence reaches a maximum around $10 \mathrm{~cm}$. The reason of this increase is that neutrons coming into the concrete interact with the hydrogens in a

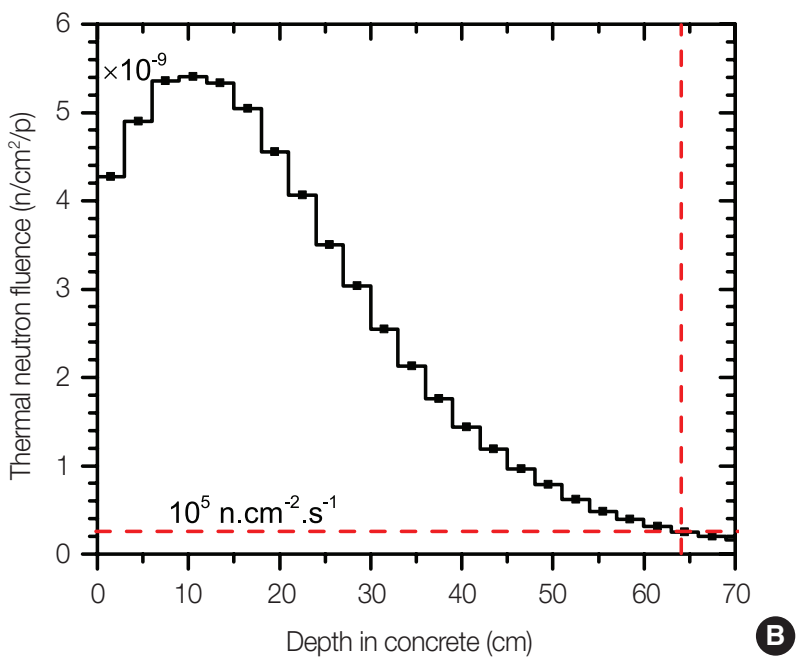

Fig. 4. (A) Neutron fluence at different concrete depths without neutron absorbing materials, (B) integrated neutron fluence (En $<0.4 \mathrm{eV}$ ) as a function of concrete thickness in the front wall indicated as position 2 in Fig. 1. The proton beam current is $60 \mu \mathrm{A}$. Horizontal and vertical dashed lines correspond to the thermal neutron flux of $10^{5} \mathrm{n} \cdot \mathrm{cm}^{-2} \cdot \mathrm{s}^{-1}$ and $64 \mathrm{~cm}$ concrete to be radioactive waste, respectively. 
concrete and are thermalized, and then reach the maximum around the depth of $10 \mathrm{~cm}$. Thermalized neutrons are captured by the elements of concrete and the number of thermal neutrons decreases after $10 \mathrm{~cm}$ depth. The level of concrete activity mainly depends on the amount of Eu and Co, and the thermal neutron flux. We measured the average values of Eu and Co as 1 and 15 ppm, respectively [18]. By considering the operation scheme of 4 hours per day, 5 days per week over 520 weeks (10 years), and the thermal neutron flux of $10^{5} \mathrm{n} \cdot \mathrm{cm}^{-2} \cdot \mathrm{s}^{-1}$, the specific activities of ${ }^{152} \mathrm{Eu}$ and ${ }^{60} \mathrm{Co}$ were matched the clearance level. In other words, where the thermal neutron flux exceeded $10^{5} \mathrm{n} \cdot \mathrm{cm}^{-2} \cdot \mathrm{s}^{-1}$, the concrete was considered as the radioactive waste in this work. The horizontal and vertical lines in Fig. 4B correspond to the thermal neutron flux of $10^{5} \mathrm{n} \cdot \mathrm{cm}^{-2} \cdot \mathrm{s}^{-1}$ and the concrete depth which it is radioactive waste, respectively. It is seen that around $64 \mathrm{~cm}$ of the concrete becomes radioactive waste in the front wall.

In the simulations, the walls were covered by the absorbing materials with different thicknesses. Table 2 shows the thickness of each material and the corresponding transmitted thermal neutrons ratios obtained as $\Phi_{\text {with shield }} / \Phi_{\text {no shield }}$ at depth of $64 \mathrm{~cm}$ in the concrete wall. The thermal neutron fluence and the $\Phi_{\text {with shield }} / \Phi_{\text {no shield }}$ versus the depth in concrete

Table 2. Neutron Absorbing Materials and Thicknesses Used in the Calculations and Corresponding Transmitted Thermal Neutrons at Depth of $64 \mathrm{~cm}$ in Concrete

\begin{tabular}{lcc}
\hline Material & Thickness $(\mathrm{cm})$ & Transmitted thermal neutrons (\%) \\
\hline $\mathrm{Gd}_{2} \mathrm{O}_{3}$ & 5 & 65 \\
& 10 & 40 \\
$\mathrm{~B}{ }_{4} \mathrm{C}$ & 15 & 25 \\
& 5 & 45 \\
& 10 & 20 \\
$\mathrm{PE}$ & 15 & 10 \\
& 5 & 58 \\
$\mathrm{BPE}$ & 10 & 31 \\
& 15 & 19 \\
& 5 & 59 \\
$\mathrm{PE}+\mathrm{Gd}_{2} \mathrm{O}_{3}$ & 10 & 35 \\
& 15 & 20 \\
& $10+10$ & 20 \\
& $10+5$ & 23 \\
& $10+0.4$ & 30 \\
$\mathrm{PE}+\mathrm{B}_{4} \mathrm{C}$ & $10+0.1$ & 30 \\
& $5+10$ & 23 \\
& $10+10$ & 7 \\
& $10+0.4$ & 30 \\
\hline
\end{tabular}

PE, polyethylene; BPE, borated polyethylene. for single materials are shown in Fig. 5 and for different combinations are shown in Fig. 6 .

Fig. 5A and 5B indicate the thermal neutron fluence against depth in concrete and corresponding ratios to case with no shield, respectively. The radioactive concrete waste in the front wall decreases to 59,58 , and $49 \mathrm{~cm}$ in depth by using 5,10 , and $15 \mathrm{~cm}$-thick $\mathrm{Gd}_{2} \mathrm{O}_{3}$ shield and transmitted thermal neutrons are $65 \%, 40 \%$, and $25 \%$, respectively. It is seen from Fig. $5 \mathrm{C}$ that $\mathrm{B}_{4} \mathrm{C}$ can reduce the concrete thickness as the radioactive waste to 55,43 , and $30 \mathrm{~cm}$. According to Fig. $5 \mathrm{D}$, the thermal neutrons decrease dramatically so that for 5,10 , and $15 \mathrm{~cm}$-thick $\mathrm{B}_{4} \mathrm{C}$, the transmitted thermal neutrons are $45 \%, 20 \%$, and $10 \%$, respectively. Although boron carbide is quite effective in thermal neutron abortion, it is one of the costly materials, in particular, for covering whole wall of cyclotron walls with thick layers.

In case of PE, thermal neutrons increase at the surface of the concrete due to thermalization process in PE. At inner positions, however, thermal neutrons are attenuated by concrete (Fig. 5E, 5F). Placing 5, 10, and $15 \mathrm{~cm}$ of PE shield, the concrete thickness as the waste is 56,48 , and $43 \mathrm{~cm}$, and the transmitted thermal neutrons are $58 \%, 31 \%$, and $19 \%$, respectively. On the other hand, for BPE, neutrons are elastically scattered by the hydrogen atoms in PE and lose energy and are absorbed by boron. Thus, the thermal neutron fluence is lower than that of only $\mathrm{PE}$ at shallow positions in the concrete. The activated thickness of the concrete after using 5,10 , and $15 \mathrm{~cm}$-thick BPE shield is 56,48 , and $43 \mathrm{~cm}$ and the transmitted neutrons are $59 \%, 35 \%$, and $20 \%$, respectively (Fig. 5G, 5H).

$10 \mathrm{~cm}$-thick $\mathrm{PE}+10 \mathrm{~cm}$-thick $\mathrm{B}_{4} \mathrm{C}$ can reduce dramatically the radioactive concrete waste to $20 \mathrm{~cm}$ in depth and the transmitted thermal neutrons to 7\% (Fig. 6A, 6B). As indicated in Fig. 6C and 6D, the activated concrete thickness is reduced to 40,45 , and $38 \mathrm{~cm}$ and the transmitted thermal neutrons reach $20 \%$ by using $10 \mathrm{~cm}$-thick $\mathrm{PE}+10 \mathrm{~cm}$-thick $\mathrm{Gd}_{2} \mathrm{O}_{3}$, and $23 \%$ for $10 \mathrm{~cm}$-thick $\mathrm{PE}+5 \mathrm{~cm}$-thick $\mathrm{Gd}_{2} \mathrm{O}_{3}$, and $5 \mathrm{~cm}$ thick $\mathrm{PE}+10 \mathrm{~cm}$-thick $\mathrm{Gd}_{2} \mathrm{O}_{3}$.

It should be mentioned that in economical view, using a large amount of these absorbing materials are not cost effective. Therefore, thin layer shields of $\mathrm{B}_{4} \mathrm{C}$ and $\mathrm{Gd}_{2} \mathrm{O}_{3}$ were placed between $10 \mathrm{~cm}$-thick $\mathrm{PE}$ and the concrete wall one by one and the results were compared together. As shown in Fig. $6 \mathrm{~A}$ and $6 \mathrm{~B}$, using 0.1 or $0.4 \mathrm{~cm}$-thick $\mathrm{B}_{4} \mathrm{C}$ layer, the thermal neutron fluence was reduced absolutely in the concrete depth up to $24 \mathrm{~cm}$. Because the fast neutrons are thermal- 

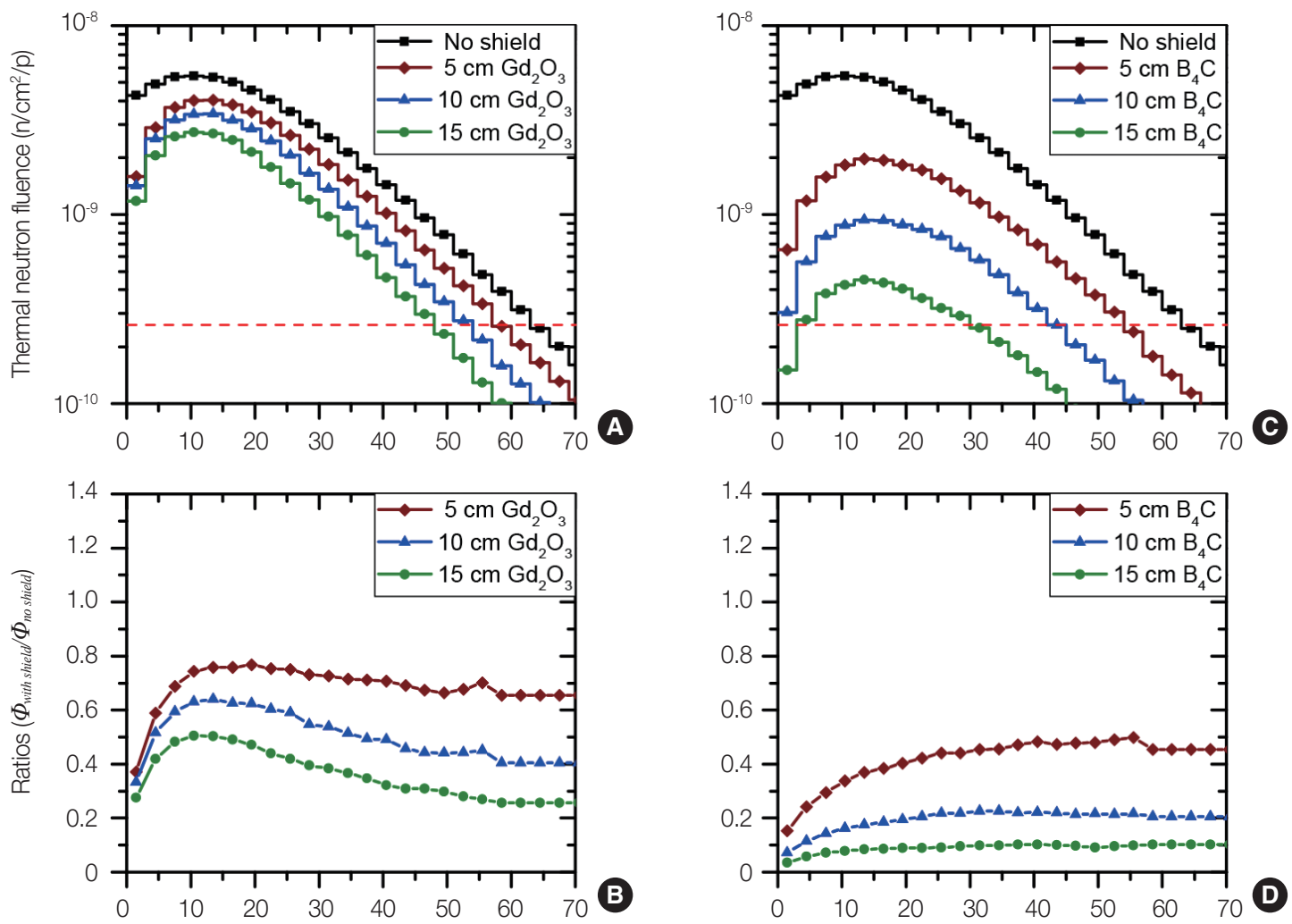

(D)
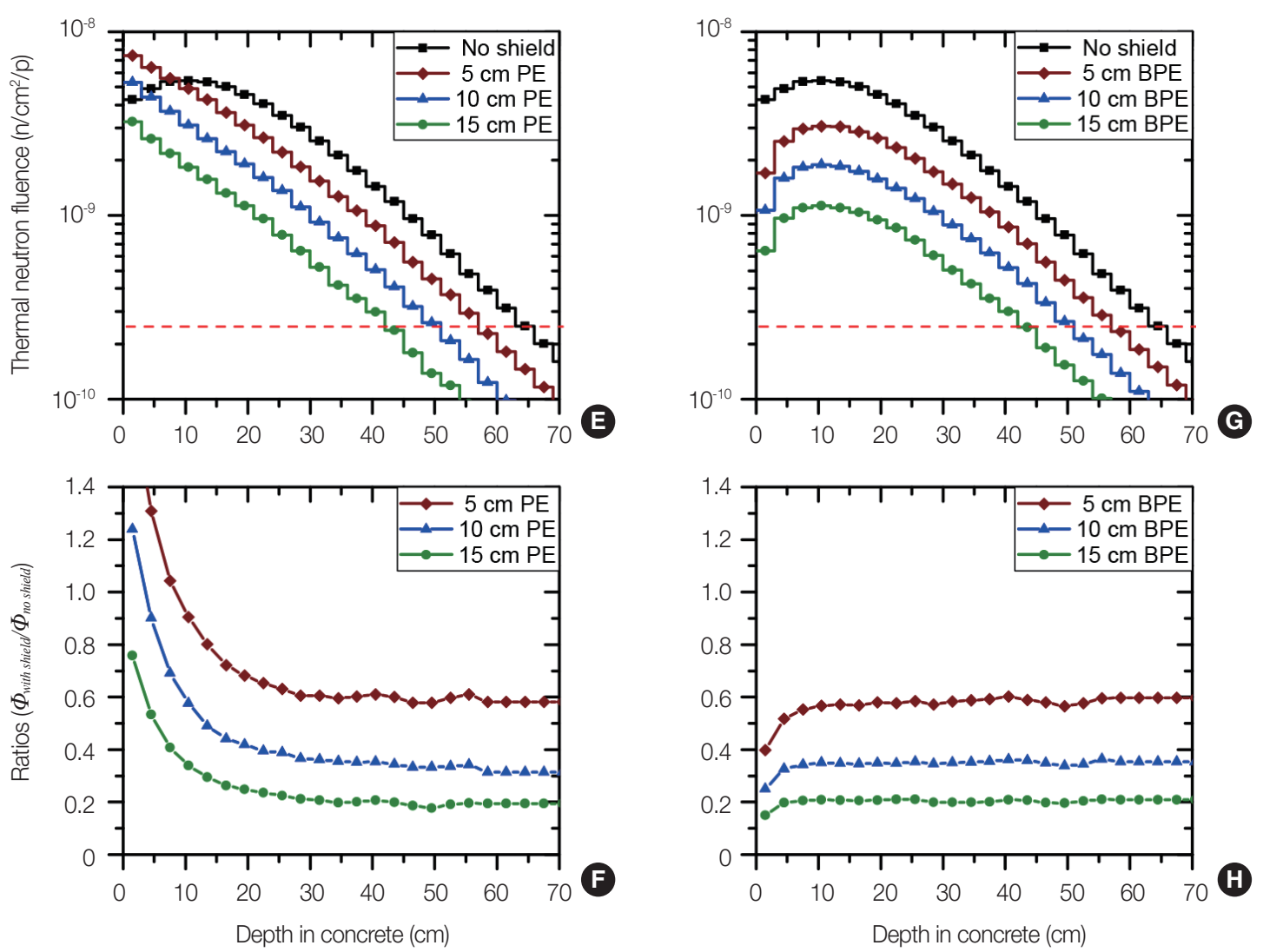

G

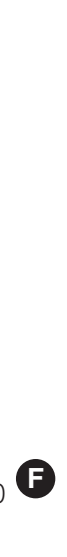

Fig. 5. Thermal neutron fluences for different neutron absorbing materials and corresponding ratios, $\left(\Phi_{\text {with shield }} / \Phi_{\text {no shield }}\right)$ as function of concrete thickness in the front wall indicated as position 2 in Fig. 1. (A, B) for $\mathrm{Gd}_{2} \mathrm{O}_{3},(C, D)$ for $\mathrm{B}_{4} \mathrm{C},(\mathrm{E}, \mathrm{F})$ for PE, and (G, H) for BPE. Horizontal dashed lines correspond to thermal neutron flux of $10^{5} \mathrm{n} \cdot \mathrm{cm}^{-2} \cdot \mathrm{s}^{-1}$. PE, polyethylene; BPE, borated polyethylene. 

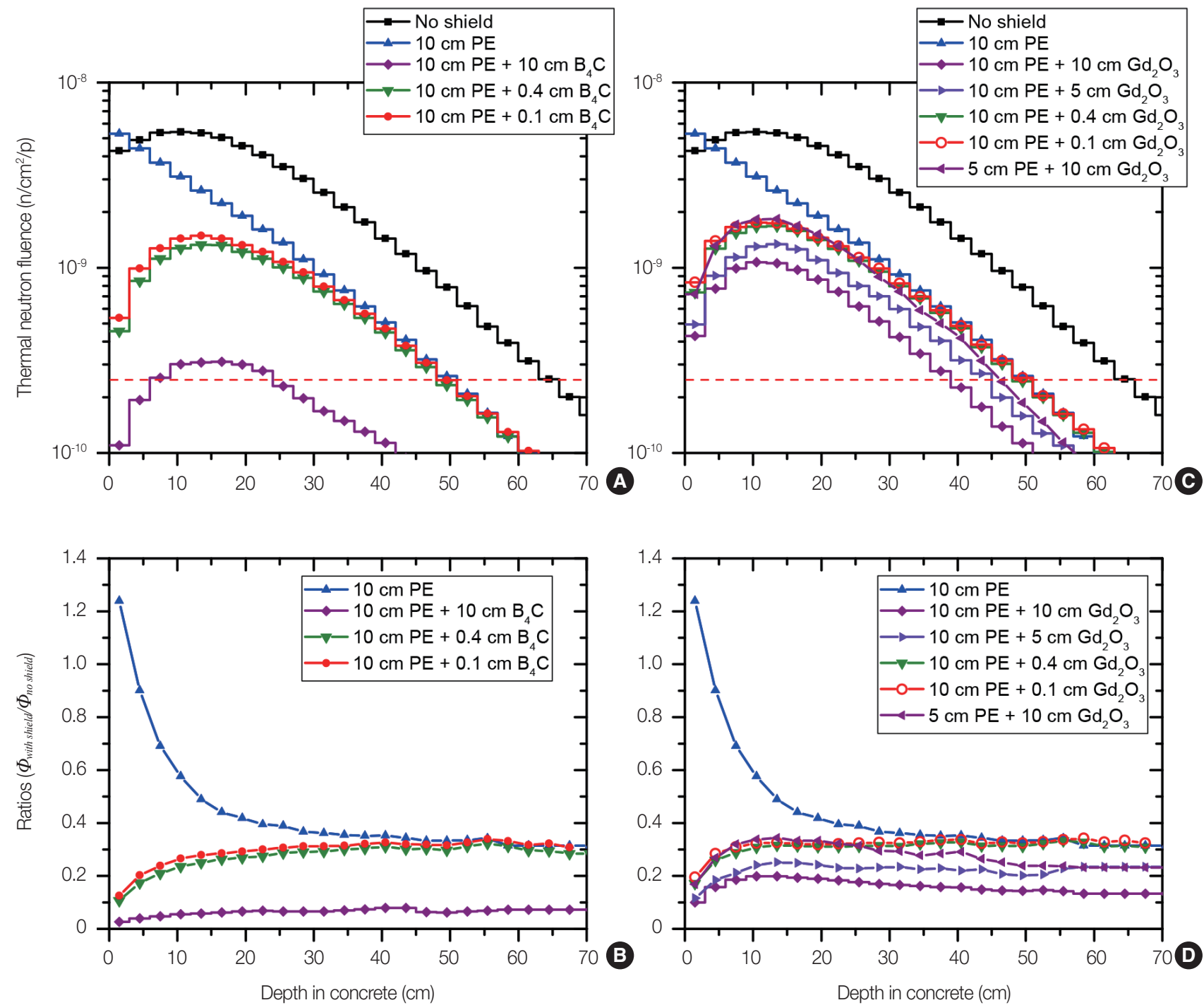

Fig. 6. Thermal neutron fluences for different neutron absorbing materials and corresponding ratios, $\left(\Phi_{\text {with shield }} / \Phi_{\text {no shield }}\right)$ as function of concrete thickness in the front wall indicated as position 2 in Fig. 1. (A, B) for $P E+B_{4} C$ and $(C, D)$ for $P E+G_{2} \mathrm{O}_{3}$. The layers of $\mathrm{B}_{4} \mathrm{C}$ and $\mathrm{Gd}_{2} \mathrm{O}_{3}$ are placed between the wall and PE. Horizontal dashed lines correspond to thermal neutron flux of $10^{5} \mathrm{n} \cdot \mathrm{cm}^{-2} \cdot \mathrm{s}^{-1}$. PE, polyethylene.

ized in the PE shield and then are absorbed by boron before the concrete wall. On the other hand, the results for $0.1 \mathrm{~cm}$ and $0.4 \mathrm{~cm}$-thick $\mathrm{B}_{4} \mathrm{C}$ with $10 \mathrm{~cm}$-thick $\mathrm{PE}$ are almost similar so as the transmitted thermal neutrons was reduced to $30 \%$. The thickness of concrete wall to be considered radioactive was also reduced to $48 \mathrm{~cm}$ in the front wall. According to Fig. 6C and 6D, the layered shields of $10 \mathrm{~cm}$-thick $\mathrm{PE}+0.4 \mathrm{~cm}$ thick $\mathrm{Gd}_{2} \mathrm{O}_{3}$ and $10 \mathrm{~cm}$-thick $\mathrm{PE}+0.1 \mathrm{~cm}$-thick $\mathrm{Gd}_{2} \mathrm{O}_{3}$ reduce the radioactive concrete thickness to $48 \mathrm{~cm}$ and the transmitted thermal neutrons were $30 \%$.

Fig. 6 illustrates the results for the front wall where the effect of $10 \mathrm{~cm}$-thick PE and $10 \mathrm{~cm}$-thick PE+0.1 cm-thick $\mathrm{B}_{4} \mathrm{C}$ on the waste reduction seems similar. However, it is obvious in Fig. 7 to figure out the effect of $\mathrm{B}_{4} \mathrm{C}$ on the radioactive waste reduction compared with only $\mathrm{PE}$ layer. The depth profile of thermal neutrons at backward and left side walls, which are indicated as position 3 and position 4 in Fig. 1, are also shown in Fig. 7. It can be seen that in backward (Fig. 7A) and left side (Fig. 7B) walls, no radioactive waste is generated by using $10 \mathrm{~cm}$-thick $\mathrm{PE}+0.1 \mathrm{~cm}$-thick $\mathrm{B}_{4} \mathrm{C}$, while the concrete waste thickness is around $20 \mathrm{~cm}$ for $10 \mathrm{~cm}$-thick PE in both positions.

By placing $0.1 \mathrm{~cm}$-thick $\mathrm{B}_{4} \mathrm{C}+10 \mathrm{~cm}$-thick $\mathrm{PE}$ or $0.1 \mathrm{~cm}$ thick $\mathrm{Gd}_{2} \mathrm{O}_{3}+10 \mathrm{~cm}$-thick PE on the concrete wall, the depth of concrete wall treated as the radioactive waste was reduced similarly, from $64 \mathrm{~cm}$ of no shield case to around $48 \mathrm{~cm}$. Al- 

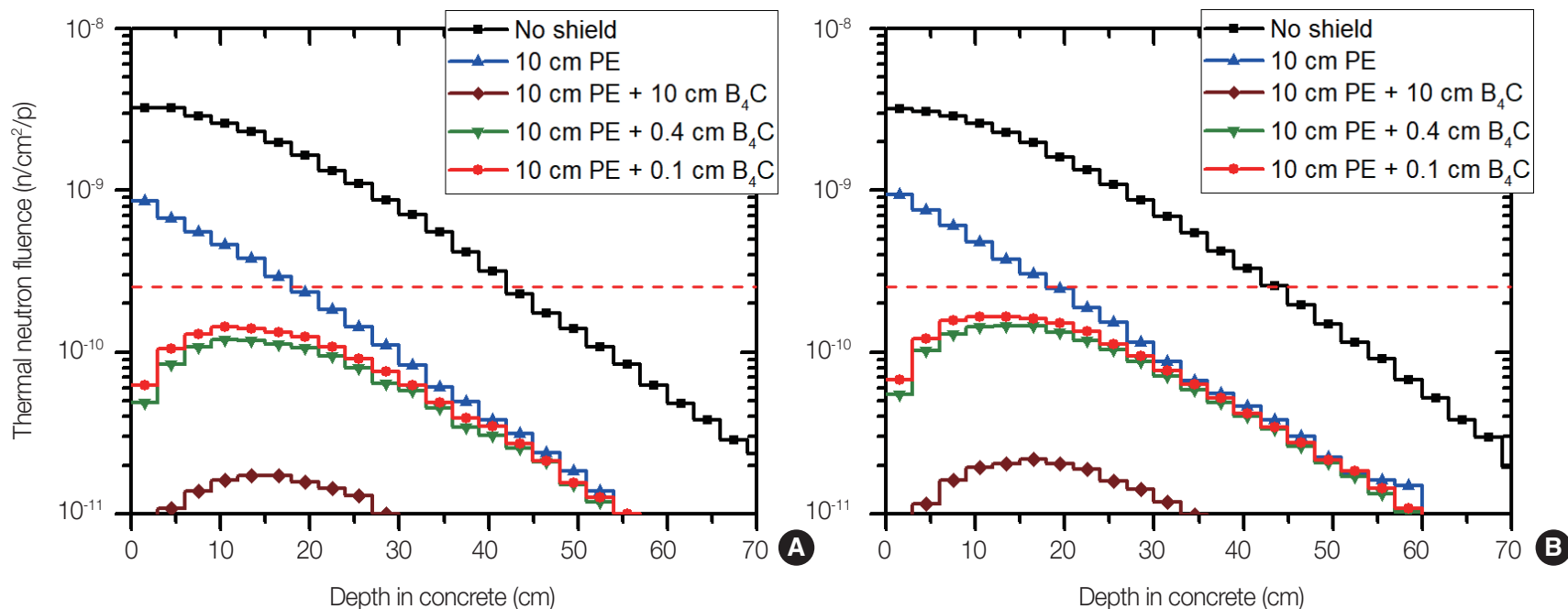

Fig. 7. Thermal neutron fluences for $\mathrm{PE}$ and $\mathrm{PE}+\mathrm{B}_{4} \mathrm{C}$ combinations as function of concrete thickness. (A) In the backward wall indicated as position 3 in Fig. 1 and (B) in the left side wall indicated as position 4 in Fig. 1. Horizontal dashed lines correspond to thermal neutron flux of $10^{5} \mathrm{n} \cdot \mathrm{cm}^{-2} \cdot \mathrm{s}^{-1}$. PE, polyethylene.

though the price of $10 \mathrm{~cm}$-thick $\mathrm{PE}+0.1 \mathrm{~cm}$-thick $\mathrm{Gd}_{2} \mathrm{O}_{3}$ is around $20 \%$ lower than that of $10 \mathrm{~cm}$-thick $\mathrm{PE}+0.1 \mathrm{~cm}$-thick $\mathrm{B}_{4} \mathrm{C}$. The $\mathrm{Gd}_{2} \mathrm{O}_{3}$ is in the form of powder and needs to be fabricated in a correct way to be used after the PE layer. On the other hand, $\mathrm{B}_{4} \mathrm{C}$ is commercially available in different forms and it is easy to be shaped and used after the PE layer. Therefore, $10 \mathrm{~cm}$-thick $\mathrm{PE}+0.1 \mathrm{~cm}$-thick $\mathrm{B}_{4} \mathrm{C}$ is considered to be the best combination as additional shielding materials.

\section{Estimation of Radioactive Concrete Reduction}

The thermal neutron versus concrete thickness shown in Fig. 6 are only for the forward direction with respect to the proton beam (front wall). In order to estimate the total reduction of radioactive concrete waste, the thermal neutron distribution inside the cyclotron room as well as all concrete walls are shown in Fig. 8 and discussed. The figures were obtained for the cases without any additional shielding material (Fig. 8A, 8B), with $10 \mathrm{~cm}$-thick PE (Fig. 8C, 8D), and with $10 \mathrm{~cm}$-thick PE+0.1 cm-thick $\mathrm{B}_{4} \mathrm{C}$ shield (Fig. 8E, 8F). Fig. 8 illustrates the thermal neutron distributions $\left(\mathrm{E}_{\mathrm{n}}<0.4 \mathrm{eV}\right)$ calculated by the PHITS code in the vertical (left column) and top views (right column). The concrete depths at which the thermal neutron exceeds $10^{5} \mathrm{n} \cdot \mathrm{cm}^{-2} \cdot \mathrm{s}^{-1}$ are indicated for each case. Without neutron absorbing materials, more than $60 \mathrm{~cm}$ of the concrete was considered to be radioactive waste in the front wall regarding the proton beam as well as in the floor and more than $40 \mathrm{~cm}$ in all other walls. By using $10 \mathrm{~cm}$ thick PE, the radioactive waste thickness in the front wall and floor is $48 \mathrm{~cm}$ and that of ceiling is $30 \mathrm{~cm}$ (Fig. 8C). The radio- active waste thickness is $20 \mathrm{~cm}$ for the left side and backward walls and $32 \mathrm{~cm}$ for the right side wall respecting to the proton beam (Fig. 8D). On the other hand, $10 \mathrm{~cm}$-thick PE+0.1 $\mathrm{cm}$-thick $\mathrm{B}_{4} \mathrm{C}$ can reduce the concrete waste thickness to 48 $\mathrm{cm}$ in the front wall as well as in the floor and $24 \mathrm{~cm}$ in the ceiling (Fig. 8E). Thickness of $28 \mathrm{~cm}$ of the concrete is radioactive waste in the right side wall regarding to the proton beam. No activated concrete was generated in the backward and left side walls (Fig. 8F).

At forward direction, the effect of $10 \mathrm{~cm}$-thick PE and 10 $\mathrm{cm}$-thick $\mathrm{PE}+0.1 \mathrm{~cm}$-thick $\mathrm{B}_{4} \mathrm{C}$ seems to be similar. For the side walls, ceiling, floor, and back wall, however, $0.1 \mathrm{~cm}$-thick $\mathrm{B}_{4} \mathrm{C}$ can absorb the scattered neutrons dramatically as can be seen from Figs. 7 and 8 . The reason is that the neutrons are scattered and become thermal and can be captured by $\mathrm{B}_{4} \mathrm{C}$. As a result, the total radioactive waste volume decreases. In the forward direction, most neutrons are epithermal and fast neutrons that cannot be captured by $\mathrm{B}_{4} \mathrm{C}$ so that the difference between the $10 \mathrm{~cm}$-thick $\mathrm{PE}$ and $10 \mathrm{~cm}$-thick $\mathrm{PE}+0.1 \mathrm{~cm}$-thick $\mathrm{B}_{4} \mathrm{C}$ is small. It is found that the amount of radioactive concrete waste can be reduced by a factor of 2 using the $10 \mathrm{~cm}$-thick $\mathrm{PE}+0.1 \mathrm{~cm}$-thick $\mathrm{B}_{4} \mathrm{C}$ shield. It can be seen from Fig. 8 that the front wall respecting to the proton beam and the floor are the hot spots where the amount of radioactive waste is quite high. Thus, $10 \mathrm{~cm}$-thick PE+0.1 cmthick $\mathrm{B}_{4} \mathrm{C}$ can be used for these areas, and for other side walls, thinner shielding materials is enough to reduce thermal neutron fluence inside the walls and results in lowering the price of the shielding materials. In a real cyclotron vault, 

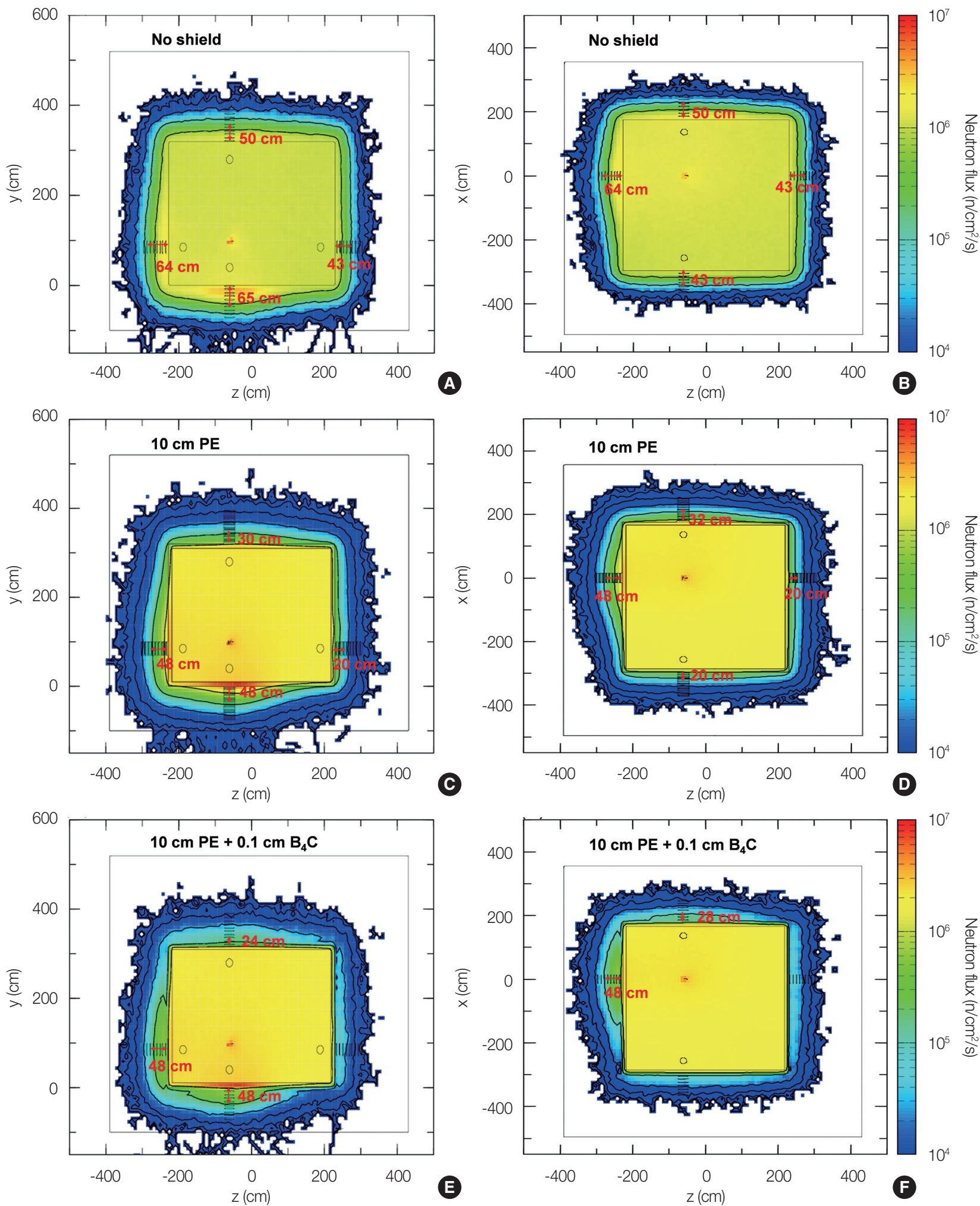

Fig. 8. Distributions of thermal neutron flux $\left(E_{n}<0.4 \mathrm{eV}\right.$ ) inside the cyclotron room and the concrete walls in vertical (left column) and top views (right column) (A, B) without neutron absorbing materials, (C, D) with $10 \mathrm{~cm}$-thick PE, and (E, F) with $10 \mathrm{~cm}$-thick PE+0.1 cm-thick $\mathrm{B}_{4} \mathrm{C}$. The thin layer of $\mathrm{B}_{4} \mathrm{C}$ is placed between the wall and $\mathrm{PE}$. The numbers indicate the depths at which thermal neutron flux exceeds $10^{5}$ $\mathrm{n} \cdot \mathrm{cm}^{-2} \cdot \mathrm{s}^{-1}$ and concrete is radioactive waste. PE, polyethylene. 
however, neutrons can be scattered by the cyclotron body remarkably and reach to the thermal energy which can be captured by boron in the $\mathrm{B}_{4} \mathrm{C}$. Therefore, $10 \mathrm{~cm}$-thick PE +0.1 cm-thick $\mathrm{B}_{4} \mathrm{C}$ is expected to be more effective to reduce the radioactive waste in concrete than the simple geometry considered in this work. It is emphasized that the operation scheme in this work was conservative so that in the case of the operations corresponding to around $20 \%$ of our operation scheme and using $10 \mathrm{~cm}$-thick PE $+0.1 \mathrm{~cm}$-thick $\mathrm{B}_{4} \mathrm{C}$, one should not consider the concrete as the radioactive waste. By considering the installation cost of the shielding material, it seems to be very beneficial to reduce the radioactive waste storage expenses.

It should be pointed out that the $\mathrm{B}_{4} \mathrm{C}$ is available in rubber form that can be shaped easily and can be attached to the walls. The amount of $\mathrm{B}_{4} \mathrm{C}$ in the rubber material is $80 \%$ and $20 \%$ is the glue to form the rubber. Therefore, the required thickness of the $\mathrm{B}_{4} \mathrm{C}$ rubber is $0.12 \mathrm{~cm}$ to make equivalent to $0.1 \mathrm{~cm}$-thick $\mathrm{B}_{4} \mathrm{C}$.

\section{Production of Other Radionuclides}

Together with the ${ }^{152} \mathrm{Eu}$ and ${ }^{60} \mathrm{Co}$ radionuclides, the ${ }^{54} \mathrm{Mn}$, ${ }^{22} \mathrm{Na}$, and ${ }^{3} \mathrm{H}$ radionuclides can be produced through the ${ }^{54} \mathrm{Fe}(\mathrm{n}, \mathrm{p}){ }^{54} \mathrm{Mn},{ }^{23} \mathrm{Na}(\mathrm{n}, 2 \mathrm{n}){ }^{22} \mathrm{Na},{ }^{2} \mathrm{H}(\mathrm{n}, \gamma){ }^{3} \mathrm{H}$, and ${ }^{6} \mathrm{Li}(\mathrm{n}, \alpha){ }^{3} \mathrm{H}$ reactions. ${ }^{54} \mathrm{Mn}$ and ${ }^{22} \mathrm{Na}$ are generated by fast neutrons so as their production were approximately in the order of ${ }^{152} \mathrm{Eu}$ and ${ }^{60} \mathrm{Co}$ at the concrete surface. The ${ }^{54} \mathrm{Mn}$ and ${ }^{22} \mathrm{Na}$ production decreased exponentially with the concrete depth and became one order lower than ${ }^{152} \mathrm{Eu}$ and ${ }^{60} \mathrm{Co}$ at $30 \mathrm{~cm}$. The production of ${ }^{3} \mathrm{H}$ in the concrete was about one order higher than other radionuclides due to the high reaction cross section of the ${ }^{6} \mathrm{Li}(\mathrm{n}, \alpha)^{3} \mathrm{H}$ reaction. These results are in agreement with the results reported in the literature [2, 13]. However, the clearance level of ${ }^{3} \mathrm{H}$ is $100 \mathrm{~Bq} \cdot \mathrm{g}^{-1}$ which is three orders higher than that of ${ }^{152} \mathrm{Eu}$ and ${ }^{60} \mathrm{Co}$. It was also confirmed that ${ }^{3} \mathrm{H}$ is produced mainly by the thermal neutrons and the transmitted thermal neutrons decrease to $30 \%$ by using the $10 \mathrm{~cm}$-thick $\mathrm{PE}+0.1 \mathrm{~cm}$-thick $\mathrm{B}_{4} \mathrm{C}$ shielding material and the production of the ${ }^{3} \mathrm{H}$ could reduce correspondingly. The number of fast neutrons at different concrete depths without and with the $10 \mathrm{~cm}$-thick $\mathrm{PE}+0.1 \mathrm{~cm}$-thick $\mathrm{B}_{4} \mathrm{C}$ shielding are shown in Fig. 9A and corresponding ratio is indicated in Fig. 9B. It is seen that the transmitted fast neutrons also decrease to $40 \%$ by using the shielding material. It means that the ${ }^{3} \mathrm{H}$, ${ }^{54} \mathrm{Mn}$, and ${ }^{22} \mathrm{Na}$ production could also decrease considerably and they could not be a major issue for the radioactive waste management of concrete.

Structural concrete is often reinforced with steel bars that become activated via ${ }^{54} \mathrm{Fe}(\mathrm{n}, \gamma){ }^{55} \mathrm{Fe},{ }^{54} \mathrm{Fe}(\mathrm{n}, \mathrm{p}){ }^{54} \mathrm{Mn}$, and ${ }^{59} \mathrm{Co}(\mathrm{n}, \gamma){ }^{60} \mathrm{Co}$ reactions. The reinforcing bars contribution to the activation can be significant [21]. However, the number of fast and thermal neutrons significantly decrease by using $10 \mathrm{~cm}$-thick $\mathrm{PE}+0.1 \mathrm{~cm}$-thick $\mathrm{B}_{4} \mathrm{C}$ as the shielding material and the activation of the reinforcing bars are also decreased proportionally. It is noticed that the activated bars are localized and could be separated from the concrete during the
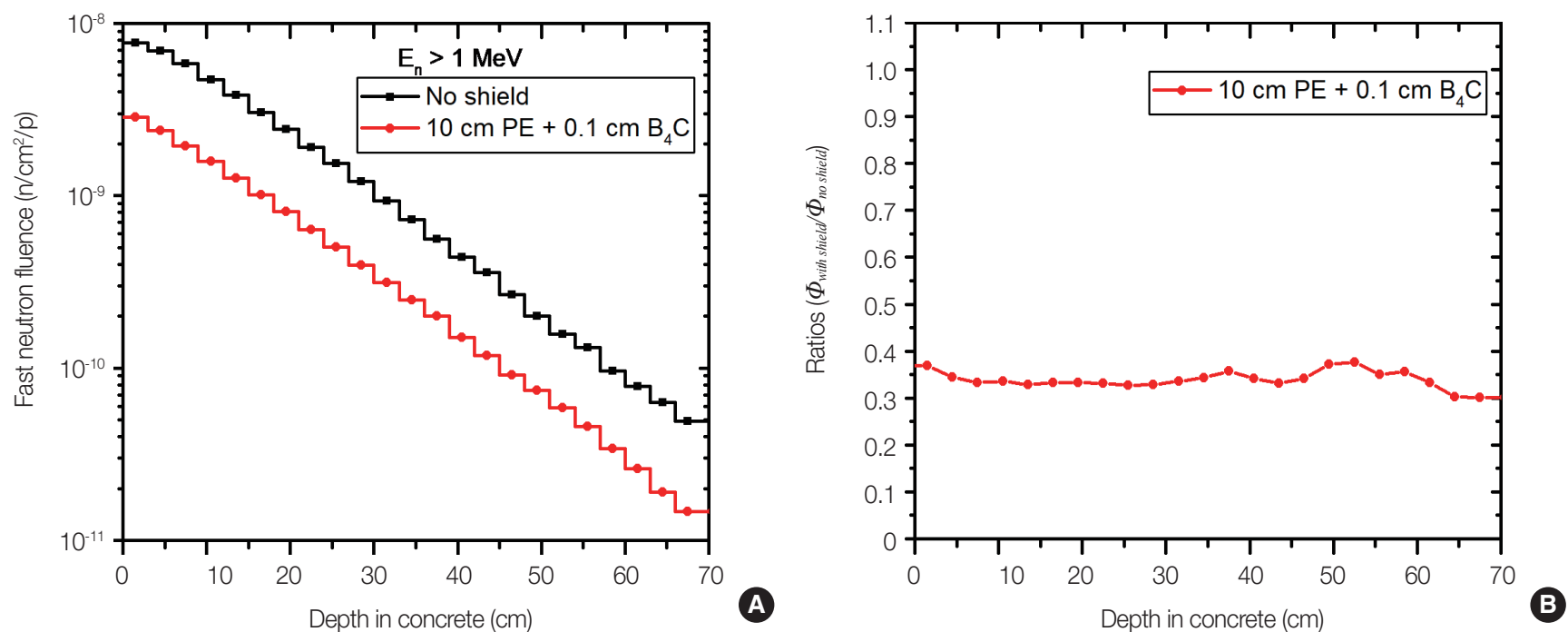

Fig. 9. (A) Fast neutron fluence $\left(E_{n}>1 \mathrm{MeV}\right)$ against the concrete depth without and with the $10 \mathrm{~cm}$-thick $P E+0.1 \mathrm{~cm}$-thick $B_{4} C$ shielding, $(B)$ transmitted fast neutrons, $\left(\Phi_{\text {with shield }} / \Phi_{\text {no shield }}\right)$ as a function of concrete thickness in the front wall indicated as position 2 in Fig. 1. PE, polyethylene. 
dismantling. They are not as voluminous as the concrete to become a major concern for the radioactive waste storage. For the case of ${ }^{54} \mathrm{Mn}$, its activation level remains constant after several years of operation [21,22]. By considering the typical cooling time before the decommissioning the activity level of ${ }^{54} \mathrm{Mn}$ could reduce as well.

\section{Conclusion}

The use of non-self-shielded cyclotrons for the PET isotopes production results in serious concrete activation after a long operation. In this study, intensive Monte Carlo calculations were performed to mitigate the concrete activation by using additional neutron absorbing materials. A non-self-shielded PETtrace cyclotron vault and an $\mathrm{H}_{2}{ }^{18} \mathrm{O}$ target was simulated by the PHITS code to study the effects of neutron absorbers on thermal neutrons reduction. The conservative cyclotron operation scheme of 4 hours per day, 5 days per week over 520 weeks (10 years) and $60 \mu \mathrm{A}$ proton beams was selected in this work. The amounts of Eu and Co were 1 and 15 $\mathrm{ppm}$, respectively. The thermal neutron flux of $10^{5} \mathrm{n} \cdot \mathrm{cm}^{-2} \cdot \mathrm{s}^{-1}$ was obtained at above specific condition, which the concrete was considered as the radioactive waste. Results showed that $\mathrm{Gd}_{2} \mathrm{O}_{3}, \mathrm{~B} 4 \mathrm{C}, \mathrm{PE}$, and BPE would be effective to decrease the activation level of concrete. However, a combination of these materials is more effective than using single shield material to decrease the price of the shielding. It was concluded that placing $0.1 \mathrm{~cm}$-thick $\mathrm{B}_{4} \mathrm{C}$ between $10 \mathrm{~cm}$-thick $\mathrm{PE}$ and the concrete wall could reduce the total radioactive concrete waste by a factor of 2 in the whole cyclotron room. However, this combination is expected to reduce more thermal neutrons in a real cyclotron vault. Additionally, the amount of radioactive waste decreases dramatically at cyclotron with lower operating parameters. By taking the price of $0.1 \mathrm{~cm}$-thick $\mathrm{B}_{4} \mathrm{C}$ and $10 \mathrm{~cm}$-thick PE into account, it is still cost-effective to use it as a shielding material to achieve a significant reduction of radioactive concrete waste volumes.

\section{Conflict of Interest}

No potential conflict of interest relevant to this article was reported.

\section{Acknowledgements}

This work was supported by the Nuclear Safety Research
Program through the Korea Foundation of Nuclear Safety (KOFONS), granted financial resource from the Nuclear Safety and Security Commission (NSSC) of Republic of Korea (No. 1303026 and 1603005).

\section{Author Contribution}

Conceptualization: Bakhtiari M. Data curation: Bakhtiari M. Funding acquisition: Lee HS. Methodology: Bakhtiari M, Mokhtari Oranj L, Jung NS, Lee A. Project administration: Lee HS. Writing - original draft: Bakhtiari M, Jung NS. Writing - review \& editing: Bakhtiari M, Mokhtari Oranj L, Lee HS. Software: Bakhtiari M. Supervision: Lee HS.

\section{References}

1. Kumagai M, Sodeyama K, Sakamoto Y, Toyoda A, Matsumura H, Ebara T, et al. Activation reduction method for a concrete wall in a cyclotron vault. J Radiat Prot Res. 2017;42:141-145.

2. Wang Q, Masumoto K, Bessho K, Matsumura H, Miura T, Shibata T. Evaluation of the radioactivity in concrete from accelerator facilities. J Radioanal Nucl Chem. 2007;273:55-58.

3. Dodd AC, Shackelton RJ, Carr DA, Ismail A. Activation of air and concrete in medical isotope production facilities. AIP Conf Proc. 2017;1845:020006.

4. International Atomic Energy Agency. Application of the concepts of exclusion, exemption and clearance: safety guide (RS-G-1.7). Vienna, Austria: International Atomic Energy Agency; 2004.

5. Sato S, Morioka A, Kinno M, Ochiai K, Hori J, Nishitani T. Experimental study on induced radioactivity in boron-doped low activation concrete for DT fusion reactors. J Nucl Sci Technol. 2004; 41(sup4):66-69.

6. Sato S, Maegawa T, Yoshimatsu K, Sato K, Nonaka A, Takakura K, et al. Development of a low activation concrete shielding wall by multi-layered structure for a fusion reactor. J Nucl Mater. 2011; 417:1131-1134.

7. Ehrlicher U, Pauli H. Waste reduction by re-use of low activated material. Proceedings of the International Conference on Radioactive Waste Management and Environmental Remediation; 2009 Oct 11-15; Liverpool, UK. p. 423-430.

8. Wang P, Tang X, Chen F, Chen D. The design, fabrication and safety evaluation of a novel spent fuel storage basket material. Nucl Eng Des. 2015;284:91-96.

9. Major B. PET cyclotron design for decommissioning and waste inventory reduction. Proceedings of the International Conference on Radioactive Waste Management and Environmental Remediation; 2009 Oct 11-15; Liverpool, UK. p. 19-24.

10. Sato T, Iwamoto Y, Hashimoto S, Ogawa T, Furuta T, Abe SI, et al. Features of particle and heavy ion transport code system (PHITS) 
version 3.02. J Nucl Sci Technol. 2018;55:684-690.

11. Bakhtiari M, Oranj LM, Jung NS, Lee A, Lee HS. Estimation of neutron production yields from $\mathrm{H}_{2}{ }^{18} \mathrm{O}$ as the ${ }^{18} \mathrm{~F}$-production target bombarded by 18-MeV protons. Radiat Phys Chem. 2020; 177:109120.

12. Fujibuchi T, Horitsugi G, Yamaguchi I, Eto A, Iwamoto Y, Obara S, et al. Comparison of neutron fluxes in an $18-\mathrm{MeV}$ unshielded cyclotron room and a 16.5-MeV self-shielded cyclotron room. Radiol Phys Technol. 2012;5:156-165.

13. Masumoto K, Miura T, Bessho K, Matsumura H, Toyoda A, Wang $\mathrm{Q}$, et al. Evaluation of radioactivity in concrete samples obtained from various accelerator facilities. Proceedings of the $2^{\text {nd }}$ Asian and Oceanic Congress for Radiation Protection (AOCRP); 2006 Oct 9-13; Beijing, China.

14. Masumoto K, Toyoda A, Eda K, Izumi Y, Shibata T. Evaluation of radioactivity induced in the accelerator building and its application to decontamination work. J Radioanal Nucl Chem. 2003; 255:465-469.

15. Boudard A, Cugnon J, David JC, Leray S, Mancusi D. New potentialities of the Liège intranuclear cascade model for reactions induced by nucleons and light charged particles. Phys Rev C. 2013; 87:014606.

16. Furihata S. Statistical analysis of light fragment production from medium energy proton-induced reactions. Nucl Instrum Methods Phys Res B. 2000;171:251-258.

17. Shibata K, Iwamoto O, Nakagawa T, Iwamoto N, Ichihara A, Kuni- eda S, et al. JENDL-4.0: a new library for nuclear science and engineering. J Nucl Sci Technol. 2011;48:1-30.

18. Lee A, Jung NS, Lee HS. Composition analysis of ordinary concrete to estimate residual isotopes in the decommissioning of particle accelerator. Proceedings of the $14^{\text {th }}$ Workshop on Shielding Aspects of Accelerators, Targets and Irradiation Facilities (SATIF-14); 2018 Oct 30-Nov 2; Gyeongju, Korea.

19. Gwon DY, Kim Y, Jeong KY, Jung NS, Lee HS. Regulation improvement of cyclotrons in the Republic of Korea through analysis of radioactivation and questionnaire on operation status. Indian J Public Health Res Dev. 2018;9:675-680.

20. Jung NS, Lee A, Oranj LM, Lee HS, Gwon DY, Kim Y, et al. Activation assessment of self-shielded and non-self-shielded PET cyclotrons. Proceedings of the $14^{\text {th }}$ Workshop on Shielding Aspects of Accelerators, Targets and Irradiation Facilities (SATIF-14); 2018 Oct 30-Nov 2; Gyeongju, Korea.

21. Vichi S, Infantino A, Zagni F, Cicoria G, Braccini S, Mostacci D, et al. Activation studies for the decommissioning of PET cyclotron bunkers by means of Monte Carlo simulations. Radiat Phys Chem. 2020;174:108966.

22. Martinez-Serrano JJ, Diez de los Rios A. Prediction of neutron induced radioactivity in the concrete walls of a PET cyclotron vault room with MCNPX. Med Phys. 2010;37:6015-6021.

23. Mughabghab SF. Neutron cross sections: neutron resonance parameters and thermal cross sections (Part B, Z=61-100). Orlando, FL: Academic Press; 1984. 